\title{
Participatory praxis as an imperative for health-related stigma research
}

\author{
Laurel Sprague ${ }^{1^{*}} \mathbb{D}$, Rima Afifi ${ }^{2}$, George Ayala ${ }^{3}$ and Musah Lumumba El-nasoor ${ }^{4}$
}

\begin{abstract}
Background: Participatory praxis is increasingly valued for the reliability, validity, and relevance of research results that it fosters. Participatory methods become an imperative in health-related stigma research, where the constitutive elements of stigma, healthcare settings, and research each operate on hierarchies that push those with less social power to the margins.

Discussion: Particularly for people who are stigmatized, participatory methods balance the scales of equity by restructuring power relationships. As such, participatory praxis facilitates a research process that is responsive to community-identified priorities and creates community ownership of the research, catalyzing policy change at multiple levels and foregrounds, and addresses risks to communities from participating in research. Additionally, through upholding the agency and leadership of communities facing stigma, it can help to mitigate stigma's harmful effects. Health-related stigma research can reduce the health inequities faced by stigmatized groups if funders and institutions require and reward community participation and if researchers commit to reflexive, participatory practices. A research agenda focused on participatory praxis in health-related stigma research could stimulate increased use of such methods.
\end{abstract}

Conclusion: For community-engaged practice to become more than an ethical aspiration, structural changes in the funding, training, publishing, and tenure processes will be necessary.

Keywords: HIV/AIDS, stigma, health, community engagement, participatory praxis, community-based participatory research

\section{Background}

Participatory praxis is increasingly valued for the reliability, validity, and relevance of research results that it fosters [1-3]. As a collection of research methods that document, acknowledge, and respect local knowledge, participatory praxis provides an approach to negotiating differences between researchers and community members such that the research perspective does not supersede community perspectives or subordinate the community in its intent or its outcomes [4]. These participatory methods take their starting point from the strengths and assets inherent in a community, rather than from a weakness and deficit perspective. Participatory praxis holds heightened importance for health-related stigma research, which focuses on the "status loss and social rejection" [5] that arise when

\footnotetext{
* Correspondence: spraguel@unaids.org

${ }^{1}$ Joint United Nations Programme on HIV/AIDS (UNAIDS), Geneva,

Switzerland

Full list of author information is available at the end of the article
}

people with, or associated with, specific health or social conditions are labeled as different and treated as undesirable, resulting in significant health inequities and disparities $[5,6]$. In health-related stigma research, the constitutive elements of stigma, healthcare settings, and research each operate on hierarchies that push those with less social power to the margins, risking further marginalization in the name of knowledge production [7]. These hierarchies are magnified when researchers from high-income countries conduct research in low- and middle-income countries without engaging local researchers or local knowledge. However, health-related stigma research can have the opposite effect - reducing the marginalization and resulting health inequities faced by stigmatized groups - if researchers commit to reflexive, participatory practices and funders and institutions require and reward meaningful community participation.

This opinion piece argues that participatory praxis in health-related stigma research is an imperative. 
Particularly for people who are stigmatized, participatory praxis can balance the scales of equity by restructuring power relationships. This is because participatory praxis in health-related stigma research inherently strives to reveal insidious power structures, expose biases, and enrich understanding of community strengths and health needs. In so doing, it offers communities that are disenfranchised opportunities to exercise agency, leadership, and value to their communities. In the next sections, we highlight key aspects of participatory praxis relevant to persons who are stigmatized, suggest needed structural changes to bolster this approach, and propose a preliminary research agenda.

Our opinion piece approaches this topic from the perspective of researchers working with disenfranchised and stigmatized communities, and offers guidance from this reality. We acknowledge that much of the movement towards participatory praxis has arisen from the struggles and revolts of those communities themselves, and their agency and voice [8]. In what follows, we do not intend to minimize these contributions, rather to offer a critical analysis that intends to lift up those struggles, revolts, and voices as a precursor to research for social change.

\section{Discussion}

\section{Continuum of participation}

Community participation exists on a continuum, with one-way communication from researchers to communities at one end and activities that constitute participatory praxis through shared leadership at the other (Fig. 1). These activities include communities actively identifying questions, reviewing protocols to maximize participation and protection of vulnerable participants, implementing research methodologies, helping to interpret results within appropriate contexts, and applying results to influence decisions $[4,9,10]$. On this continuum, research with minimal engagement results in further objectification of stigmatized people, heightening risks for discrimination, humiliation, criminalization, and violence. By contrast, participatory methods result in enhanced agency, dignity, and wellbeing [2, 4].

Working within this continuum, there are different kinds of participatory praxis as well as different levels of engagement. In situations in which researchers are unable at a given point in time to reach shared leadership, a clear articulation of values, principles, and orientation are useful for conceptualizing how to ensure stigmatized communities are engaged in ways that provide a maximum amount of respect, agency, and dignity. Principles and orientations have been described extensively in community-based participatory research - one form of participatory praxis - and include commitment to co-learning, capacity-building, joint benefit, decreasing inequities, and social change [4, 11, 12]. We expand on these values below. We posit that - at every point in the research process (from development of research questions to dissemination of results) - realization of these principles, orientation, and values is possible and necessary, even if the goal of shared leadership is not achievable in the short term. Moreover, research projects that are initially characterized by the ownership and control

Increasing Level of Community Involvement, Impact, Trust, and Communication Flow

\begin{tabular}{|c|c|c|c|c|}
\hline Outreach & Consult & Involve & Collaborate & Shared Leadership \\
\hline $\begin{array}{l}\text { Some Community } \\
\text { Involvement } \\
\text { Communication flows } \\
\text { from one to the other, to } \\
\text { inform } \\
\text { Provides community with } \\
\text { information. } \\
\text { Entities coexist. } \\
\text { Outcomes: Optimally, } \\
\text { establishes communica- } \\
\text { tion channels and chan- } \\
\text { nels for outreach. }\end{array}$ & $\begin{array}{l}\text { More Community } \\
\text { Involvement } \\
\text { Communication flows to } \\
\text { the community and then } \\
\text { back, answer seeking } \\
\text { Gets information or feed- } \\
\text { back from the community. } \\
\text { Entities share information. } \\
\text { Outcomes: Develops con- } \\
\text { nections. }\end{array}$ & $\begin{array}{l}\text { Better Community } \\
\text { Involvement } \\
\text { Communication flows } \\
\text { both ways, participatory } \\
\text { form of communication } \\
\text { Involves more participa- } \\
\text { tion with community on } \\
\text { issues. } \\
\text { Entities cooperate with } \\
\text { each other. } \\
\text { Outcomes: Visibility of } \\
\text { partnership established } \\
\text { with increased coopera- } \\
\text { tion. }\end{array}$ & $\begin{array}{l}\text { Community Involvement } \\
\text { Communication flow is } \\
\text { bidirectional } \\
\text { Forms partnerships with } \\
\text { community on each } \\
\text { aspect of project from } \\
\text { development to solution. } \\
\text { Entities form bidirectional } \\
\text { communication channels. } \\
\text { Outcomes: Partnership } \\
\text { building, trust building. }\end{array}$ & $\begin{array}{l}\text { Strong Bidirectional } \\
\text { Relationship } \\
\text { Final decision making is } \\
\text { at community level. } \\
\text { Entities have formed } \\
\text { strong partnership } \\
\text { structures. } \\
\text { Outcomes: Broader } \\
\text { health outcomes affect- } \\
\text { ing broader community. } \\
\text { Strong bidirectional trust } \\
\text { built. }\end{array}$ \\
\hline
\end{tabular}

Fig. 1 Continuum of community participation in research. Adapted from [9] with permission from the International Association for Public Participation 
of research institutions retain the potential to shift over time, if approached intentionally, to a position of shared leadership with communities [12].

\section{Foundational values of participatory praxis}

A set of values focused on equity and engagement grounds participatory praxis (Table 1). Engaging stigmatized communities, including women, people living with illness or disability, lesbian, gay, bisexual, and transgender people, people of color, migrants, refugees, young people, economically disadvantaged people, and people who are institutionalized, requires researchers to un-learn practices that instill hierarchy and distance and a false researcher-subject dichotomy. With such training and reflexivity, researchers learn to make space for communities to determine the research questions and appropriate research methods.

At times, participatory praxis may seem unachievable, particularly for researchers who are not a member of the community that is being studied. Three points are essential to note. First, everyone exists at a particular intersection of privilege and oppression; acknowledging this fact is a first step in putting the values of accountability, non-othering, and dignity into practice. Second, a reflexive understanding of one's own situatedness vis á vis different statuses of power and privilege is critical for effecting participatory praxis. Membership in a particular community is not a precursor to participatory praxis. In fact, even - and perhaps especially - researchers from the community must also navigate their privilege, for example, as related to institutional, economic, or educational status, as well as gender, race, dis/ability, and other statuses. Third, in order to uphold the values of equity, justice, and flipping power dynamics, participatory praxis must be viewed as a long-term mission. Un-learning practices that instill hierarchy and distance requires constant engagement and commitment to the the values listed in Table 1 .

As participatory praxis strives to reveal power relations and expose biases, enriching the collective understanding of community strengths and needs, it contributes to an iterative cycle of learning and approaches that respond to changing needs [4]. This orientation calls for exchanging terms like 'recruitment' and 'technology transfer' for 'partnership' and 'capacity exchange' [13]. When these happen, participatory praxis facilitates a research process that is responsive to community-identified priorities, creates a sense of community ownership, foregrounds and addresses risks to communities from participating in research, and has the potential to undo stigma [14].

\section{Research led by the community, based on community- identified priorities}

Participatory praxis ensures that, when research is conducted, it has been designed to meet community-identified priorities. In 2010, 2012, and 2014, MPact Global Action for Gay Men's Health and Rights (formerly known as the Global Forum on Men Who Have Sex with Men and HIV) created and administered the Global Men's Health and Rights study, a multilingual, international, online survey involving men who have sex with men [15-17]. MPact is a network of advocates and service providers working to ensure equitable access to health services for gay men and other men who have sex with men, while promoting their health and human rights worldwide. The survey gathered information about the barriers to and facilitators of HIV

Table 1 Foundational values for participatory praxis in health-related stigma research

\begin{tabular}{|c|c|}
\hline Equity & $\begin{array}{l}\text { Research is designed and conducted with the goal of social egalitarianism that improves health and well-being for marginalized } \\
\text { groups. Researchers and communities are co-equal investigators with different sets of skills and experiences to share with each } \\
\text { other }\end{array}$ \\
\hline Justice & $\begin{array}{l}\text { Research is designed and conducted with the goal of creating social change that increases access to the rights and } \\
\text { privileges of citizenship, including access to healthcare, recourse for discrimination, and voice in decision-making and } \\
\text { policies for marginalized groups }\end{array}$ \\
\hline Dignity & The inherent worth and value of all participants is recognized at every stage of the research \\
\hline Participation & $\begin{array}{l}\text { The people and communities that are the subjects of research should lead the research and be meaningfully engaged at } \\
\text { all stages, including the right not to participate }\end{array}$ \\
\hline Non-othering & $\begin{array}{l}\text { People and communities who are the foci of research are seen as similar to the researchers, and approached from a } \\
\text { common base of humanity, rather than seen as essentially different, exotic, incomprehensible, or 'other' }\end{array}$ \\
\hline Accountability & $\begin{array}{l}\text { Communities and researchers hold themselves and each other accountable to their commitments, including to } \\
\text { participatory praxis }\end{array}$ \\
\hline Reflexivity & $\begin{array}{l}\text { Researchers and communities engage in self-reflection to examine their own stigmatizing attitudes and biases and } \\
\text { commit to rigorously seeking out and addressing their own prejudices and to refrain from acting on them }\end{array}$ \\
\hline Transparency & The rules for decision-making are clear, collective, agreed in advance, and followed \\
\hline Flipping power dynamics & $\begin{array}{l}\text { Research is designed and conducted with the goal of creating social change that results in marginalized groups gaining } \\
\text { greater control and self-determination over their lives and environments }\end{array}$ \\
\hline
\end{tabular}


services. Findings documented strong associations between experienced homophobia, provider stigma, and compromised access to HIV services and revealed important associations between connections to gay community, access, and service utilization. Because the survey was designed by and for gay men and other men who have sex with men, advocates had the information that they needed to inform WHO guidelines on effective interventions for gay and bisexual men and field guidelines for implementing sensitized programs in low- and middle-income countries $[18,19]$. The Global Men's Health and Rights study helped advocates demonstrate the importance of community-led service delivery and why addressing stigma and discrimination is essential for optimizing service uptake.

\section{Community ownership of the research results}

When participatory approaches are used, then communities own the process and the results, either fully or in partnership with formal researchers. Community ownership of research results leads to programming that can be responsive to evolving needs at multiple levels. For example, in 2014, young people living with HIV in Kenya and Uganda conducted surveys with other young people living with HIV, healthcare providers, and policy-makers to learn about access to sexual and reproductive health services and knowledge regarding the social, health, and prevention needs of young people living with HIV. The research demonstrated the critical role of providers in shaping sexual behaviors and fertility desires of young people living with HIV, yet found that provider-initiated information increased stigma and was not comprehensive. In 2015, Ugandan young people living with HIV used the survey findings to influence the Uganda Ministry of Health to include health promotion, access to integrated sexual and reproductive health, and rights and HIV services, as well as empowerment programs in the adolescent service and care package.

\section{Potential risks to community members foregrounded and addressed}

Participatory engagement of stigmatized populations in research carries risk, including being jailed, attacked, or killed in repressive countries, and stigmatized or identified as a marginalized group member more generally [20-22]. Therefore, the perceived futility of participation or need for self-preservation may impact participation [22]. Alternately, marginalized populations may choose the risks of participation over those of doing nothing. As one researcher has noted regarding Indigenous young people in Guatemala, "[f] or historically oppressed groups coming-of-age in high-risk settings, empowerment and endangerment are inevitably entwined" [20].

Participatory praxis provides the context to support community voice and minimize risks. Establishing community advisory boards has facilitated youth participation and decreased barriers in HIV research [22]. Further, establishing partnerships with community organizations has enhanced recruitment of underserved communities in population health research projects [23]. In Lebanon, the participation of staff members from community-based NGOs serving men who have sex with men, injection drug users, commercial sex workers, and individuals in prison was critical in minimizing 'harms' from participation and enhancing benefits in a biobehavioral HIV survey [21]. While participatory praxis can appear to be an unaffordable luxury when conducting research in dangerous or repressive settings, in reality, stigmatized groups are in greater danger from research in which they are not meaningfully involved or in which they do not experience shared leadership. Community members understand their context and the risks they face and can train researchers in the best practices for engagement while protecting their confidentiality and safety.

\section{Undoing stigma}

Engaging with communities as leaders, experts, and agents for change in addressing health stigma not only creates stronger and safer research studies and more relevant evidence, but can also directly affect the internal stigma that these communities face as a result of the stigma in societies. As one example, using a reflexive narrative methodology, Spieldenner et al. [24] explore the effects of participatory praxis on formal researchers and community members in three People Living with HIV Stigma Index implementations in the US. The author group, comprised of formal and community researchers who led the project, asked themselves a series of questions about the outcomes that they experienced through their work on the project. The text analysis identifies categories of change, including an increase in personal agency, as participants describe the transition from being viewed as a 'consumer', seen as a passive and patronizing identity, to being a researcher and a content matter expert, helping to collect data that is meaningful for their communities. They highlight the benefit for self-efficacy and self-esteem from working together on a common goal with other people similarly situated. They focus on moments when stigma among themselves and within the community emerged and used opportunities that participatory praxis provided to respond to that stigma. Finally, they note the high rates of economic fragility among people living with HIV who completed the survey. They expressed how important it was that the project did not expect people with HIV to work as volunteers but, instead, paid them for their work as project managers, trainers, interviewers, and for advisory work. Working in partnership with communities that are 
stigmatized creates awareness of what stigma looks like in concrete terms, and highlights to those outside the community how their actions and words may implicitly stigmatize.

Further evidence for the beneficial outcomes to communities of engaging in participatory research include greater overall health and mental health, bonding with others, and greater self-efficacy [12], while involvement in collaborative action for social justice, a critical component of participatory praxis, is linked to higher levels of political engagement over time [25] and an "enhanced sense of self, belief in change, and empowerment" [26].

\section{Supportive structural changes in funding, training, publication, promotion, and tenure processes}

Beyond individual-level commitments to participatory praxis and shared leadership, structural changes will be necessary for a change in research culture that values equally the experiences of stigmatized communities. The training of researchers in the biomedical sciences largely focuses on a particular scientific approach, with its concomitant realism ontology, etic ${ }^{1}$ epistemology, and quantitative methods. Training of researchers in the health sciences as well as the social sciences also tends towards these paradigms. Yet, participatory research is based primarily on relativism, emic ${ }^{2}$ approaches, and mixed methods, with qualitative methods providing strong evidence. Even when facilitators working in participatory action research programs are trained in participatory methods, the potency of the scientific method interferes with their ability to engage most effectively to raise community voices [27]. For example, effective facilitation of participatory praxis entails disposing of the 'expert' cloak, as well as discarding the notion of one truth. Indeed, participatory praxis requires un-learning practices that instill hierarchy and distance. For participatory praxis to thrive, a fundamental shift in training of future researchers is critical for them to acquire competency in both positivistic and non-positivistic research traditions, and view them as equally robust, valid, and reliable. Guidance on how to begin this process can be found in the writings of community-engaged academics [28], but a paradigm shift is needed. Only recently, in 2016, did the Council on Education for Public Health include qualitative methods as a required foundational competency for masters and doctor of public health students in accredited public health programs and schools [29].

The positivistic approach has pervaded what are considered to be indicators of impact in research and what is, therefore, publishable. Cook and Roche, in an editorial to the recent special issue of Educational Action Research, focused on The Conceptualisation and Articulation of Impact: Hopes, Expectations and Challenges for the Participatory Paradigm, suggesting that "[f]or participatory researchers and their partners (community members/practitioners/decision-makers), understandings of impact seldom map neatly onto conventional indicators or simplistic metrics. Research that has participatory practices at its centre is likely to have different types of impact from research that starts from a position of distanced objectivity" [30]. One way that universities and academic centers can incentivize and reward the use of participatory praxis is by including information about community engagement in publications and including community stakeholders in review processes.

Engaging in participatory praxis requires a period of trust-building and reflexivity, ahead of the joint work of identifying needs and assets. Researchers and practitioners engaging in this type of work are often disadvantaged by tenure and promotion guidelines that are built on quicker quantitative positivistic approaches to research productivity. Further, these characteristics of participatory praxis are often also at odds with funding cycles and grant requirements. For real movement toward participatory praxis, funders will need to prioritize participatory praxis when funding health-related stigma research, perhaps through special requests for proposals. Health-related stigma research can reduce the health inequities faced by stigmatized groups if funders, institutions, and academic peer-reviewed journals require and reward participatory research and practice.

\section{Towards a research agenda for participatory praxis in health-related stigma research}

An examination of current practices, gaps, and opportunities could enhance understanding of the state of participatory praxis in health-related stigma research and increase the use of such approaches or methods. A research agenda for participatory praxis in health-related stigma research is suggested in Box 1.

\section{Conclusion}

Participatory praxis is an ethical imperative when conducting health-related stigma research. Yet, for community-engaged practice to become more than an ethical aspiration, and for researchers to be supported and encouraged to adopt these approaches, structural changes in the funding, training, promotion, publishing, and tenure processes will be necessary. A variety of resources are available to researchers committed to re-balancing the scales of equity and justice, and enhancing dignity for persons and communities who are stigmatized (Box 2).

Participatory praxis has the potential to balance historical injustice and enhance equity while achieving better health outcomes. However, health-related stigma research is frequently conducted without meaningful inclusion of those who are stigmatized in the research process. Such research risks reinforcing the prejudices 
that frame stigmatized people as less than full members of their communities or as problems to be solved (by others) rather than experts in their own experience and leaders in their own emancipation. Further, non-participatory research into health-related stigma may utilize what are often scarce resources for research on study designs that lack internal validity and are irrelevant for meeting community needs. By contrast, participatory praxis in health-related stigma research enriches the understanding of community strengths as well as health needs and priorities, and helps to balance the scales of equity. This research is designed to ensure that community priorities, rather than those of individual researchers, are centered in health-stigma research, that communities own the research results that they can use to advocate for better treatment, that proper attention and mitigation are provided for the potential risks that community members might face as a result of their participation in research, and that the act of engaging in research leads to undoing, rather than perpetuating, stigma.

\section{Box $1 \mathrm{~A}$ research agenda for participatory praxis in health-related stigma research}

A systematic review of existing health-related stigma research studies to document when, where, and how communities were engaged, with particular attention to documenting how participatory praxis is employed across different health conditions and stigma types.

Process evaluations that highlight the ways in which the values listed in Table 1 have been enacted for enhanced participatory praxis, and how they have affected the undoing of stigma and movement towards the goal of social change.

Research to identify the impact of using participatory praxis, considering innovative and non-traditional indicators.

Exploratory studies to identify differential values that community members and researchers bring to such processes, factors that facilitate more meaningful community engagement in research, mechanisms through which community participation in research influences internalized stigma and enacted stigma, links between participatory praxis and increased health equity, and secondary drawbacks and gains from the uses of participatory praxis in health-related stigma research.

Multi-method explorations and modeling to examine how structural changes could have a high impact for increasing participatory praxis, such as through shifts in funding priorities to favor the adoption of participatory methods in research projects studying health-related stigma, the use of participatory approaches and their timetables, and changes in university hiring and tenure processes.

\section{Box 2 Participatory praxis resources}

Participatory Praxis Resources for Health Research: A Starting Point

Minkler M, Wallerstein N (Editors). Community-based Participatory Research for Health. San Francisco, CA: John Wiley \& Sons, Inc.; 2017.

Israel BA, Eng E, Shultz AJ, Parker EA (Editors). Methods for Community-based Participatory Research for Health. San Francisco, CA: Jossey-Bass, Inc:; 2012.

Principles of Community Engagement, Second Edition. The Clinical and Translational Science Awards Consortium, Community Engagement Key Function Committee, Task Force on the Principles of Community Engagement. 2011. Bethesda, MD: US National Institutes of Health. https://www.atsdr.cdc.gov/ communityengagement/pdf/PCE_Report_508_FINAL.pdf. Accessed 17 Jan 2019.

CARE: Community Alliance for Research and Engagement. Principles and Guidelines for Community-University Research Partnerships. New Haven, CT: Yale University; 2009. International HIV/AIDS Alliance, Academy for Educational Development, and International Center for Research on Women. Understanding and Challenging HIV-related Stigma and Discrimination: A Toolkit for Action. 2007. https://www.icrw.org/publications/understanding-and-challenging-hiv-stigma-toolkit-for-action/. Accessed 17 Jan 2019.

Wallerstein NB, Duran B. Using community-based participatory research to address health disparities. Health Promotion Practice. 2006;7(3):312-23. doi:10.1177/1524839906289376.

\section{Endnotes}

${ }^{1}$ Etic approaches focus on meanings that come from outside the community which is the subject of a study. Etic epistemologies are developed by communities of scientists and researchers, using conceptual categories and hypotheses that are agreed to be important and are viewed as universal, or as undergoing hypothesis testing for potential universality.

${ }^{2}$ Emic approaches focus on meaning as understood within a particular group of people. Emic epistemologies can be identified only by close listening to and engagement with the community that is the subject of a study.

\section{Acknowledgements}

This article is part of a collection that draws upon a 2017 workshop on stigma research and global health, which was organized by the Fogarty International Center, National Institute of Health, United States. The article was supported by a generous contribution by the Fogarty International Center. The authors thank the people living with HIV, LGBT people and young people who shared their experiences and without whom the research examples provided here would not have been possible. 


\section{Funding}

The Gay Men's Health and Rights Survey was funded by the Ministry of Foreign Affairs, the Netherlands' Bridging the Gaps Program, and the USAID/ PEPFAR/LINKAGES Program.

The biobehavioral survey was funded by the National AIDS Control Programme, Ministry of Public Health (NAP-MOPH), Lebanon, through the World Bank Group-provided funds under the Institutional Development Fund Grant for Strengthening the National HIV/AIDS Monitoring and Evaluation and Surveillance Systems in Lebanon (TF 054952 LE).

The Kenya and Uganda Young People Living with HIV study on sexual and reproductive health and rights was funded by the Global Network of People Living with HIV and Stop AIDS Now!, through funding from the Netherlands Ministry of Foreign Affairs.

The Ittleson Foundation in New York City, the Louisiana Public Health Institute, and AIDS United (Washington DC) provided generous support for the US People Living with HIV Stigma Index.

\section{Availability of data and materials}

Data from the Gay Men's Health and Rights Survey is available by request to George Ayala at gayala@mpact.org. Data and reports from the Kenya and Uganda young people living with HIV study on sexual and reproductive health and rights is available from the Uganda Network of Young People Living with HIV (UNYPA) by request to Musah Lumumba El-nasoor at msmusah71@gmail.com.

\section{Authors' contributions}

LS wrote the initial draft. RA, GA, and LM contributed research findings and examples. LS, RA, and GA revised and edited the final manuscript. All authors read and approved the final manuscript.

\section{Authors' information}

Laurel Sprague, PhD, has supported participatory research and action projects by and for networks of people living with HIV and key population communities in sub-Saharan Africa, Eastern Europe and Central Asia, and North America since 2008. Her research focuses on the resilience and resistance of marginalized communities in the face of stigma, discrimination, and criminalization. She previously taught Political Science at Wayne State University.

Rima Afifi, PhD, is a professor in the College of Public Health of the University of lowa. She has conducted research for over 20 years with communities in the Arab world. Whenever possible, she uses methods of community-based participatory research, which give marginalized communities voice and opportunities for self-determination.

George Ayala, PsyD, is the Executive Director of Mpact Global Action for Gay Men's Health and Rights (formerly The Global Forum on MSM \& HIV). A clinical psychologist and social science researcher by training, Dr. Ayala has more than 25 years of experience working in community-based organizations.

Musah Lumumba El-nasoor is a medical student at Kampala International University, who has emerged from the community of people living with HIV as a young leader. Since 2004, Musah has been involved in advocacy for policies and programs that meet the emerging sexual, reproductive, mental health, and treatment needs for adolescents and young people living with HIV, nationally, regionally, and globally.

The views expressed are solely those of the authors and do not represent those of UNAIDS.

\section{Ethics approval and consent to participate}

Not applicable.

\section{Consent for publication}

Not applicable.

\section{Competing interests}

The authors declare that they have no competing interests.

\section{Publisher's Note}

Springer Nature remains neutral with regard to jurisdictional claims in published maps and institutional affiliations.

\section{Author details}

'Joint United Nations Programme on HIV/AIDS (UNAIDS), Geneva, Switzerland. ${ }^{2}$ College of Public Health, University of lowa, lowa City, lowa,
USA. ${ }^{3}$ MPact Global Action for Gay Men's Health and Rights, Oakland, California, USA. ${ }^{4}$ Uganda Youth Coalition on Adolescent SRHR and HIV, Busia, Uganda.

Received: 1 June 2018 Accepted: 17 January 2019

Published online: 15 February 2019

\section{References}

1. Horowitz CR, Brenner BL, Lachapelle S, Amara DA, Arniella G. Effective recruitment of minority populations through community-led strategies. Am J Prev Med. 2009;37(6 Suppl 1):S195-200. https://doi.org/10.1016/j.amepre. 2009.08.006.

2. Sofolahan-Oladeinde Y, Mullins CD, Baquet CR. Using community-based participatory research in patient-centered outcomes research to address health disparities in under-represented communities. J Comp Eff Res. 2015; 4(5):515-23.

3. Patel DI, Winkler P, Botello J, Villareal J, Puga F. The citizen scientist: community-academic partnerships through Translational Advisory Boards. Patient Educ Couns. 2016;99:2087-90. https://doi.org/10.1016/j.pec.2016.07.013.

4. Wallerstein N, Duran B. Theoretical, historical and practice roots of communitybased participatory research. In: Minkler M, Wallerstein N, editors. Communitybased participatory research for health. San Francisco: Wiley; 2017. p. 17-30.

5. Link BG, Phelan JC. Conceptualizing stigma. Annu Rev Sociol. 2001;27:363-85.

6. Phelan JC, Lucas JW, Ridgeway CL, Taylor CJ. Stigma, status, and population health. Soc Sci Med. 2014;103:15-23. https://doi.org/10.1016/j.socscimed. 2013.10.004.

7. Cunningham Erves J, Mayo-Gamble TL, Malin-Fair A, Boyer A, Joosten Y, Vaugh YC, Sherden L, Luther P, Miller S, Wilkins CH. Needs, priorities, and recommendations for engaging underrepresented populations in clinical research: a community perspective. J Commun Health. 2017:42:472-80. https://doi.org/10.1007/s10900-016-0279-2.

8. Glassman M, Erdem G. Participatory action research and its meanings: vivencia, praxis, conscientization. Adult Educ Q. 2014;64(3):206-21 https:// doi.org/10.1177/0741713614523667

9. DJ MC, MA MD, Cook C, Heurtin-Roberts S, Updegrove S, Sampson D, Gutter S, Eder M. Community Engagement: Definitions and Organizing Concepts from the Literature. In: The Clinical and Translational Science Awards Consortium, Community Engagement Key Function Committee, Task Force on the Principles of Community Engagement. Principles of Community Engagement. 2nd ed. Bethesda: US National Institutes of Health; 2011. p. 1-42. https://www.atsdr.cdc.gov/ communityengagement/pdf/PCE Report 508 FINAL.pdf. Accessed 30 Sept 2018.

10. Simwinga M, Porter J, Bond V. Who is answerable to whom? Exploring the complex relationship between researchers, community and Community Advisory Board (CAB) members in two research studies in Zambia. Crit Public Health. 2018;28(3):318-28.

11. Israel BA, Schulz AJ, Parker EA, Becker AB, Allen AJ, Guzman R. Critical issues in developing and following community-based participatory research principles. In: Minkler M, Wallerstein N, editors. Communitybased Participatory Research for Health. San Francisco: Jossey-Bass; 2003. p. $53-76$

12. Wallerstein NB, Duran B. Using community-based participatory research to address health disparities. Health Promot Pract. 2006:7(3):312-23.

13. Tai-Seale M, Sullivan G, Cheney A, Thomas K, Frosch D. The language of engagement: "Aha!" moments from engaging patients and community partners in two pilot projects of the Patient-Centered Outcomes Research Institute. Perm J. 2016;20(2):89-92. https://doi.org/10.7812/TPP/15-123.

14. Canadian Aboriginal AIDS Network National Strategies. http://caan.ca/ national-aboriginal-strategies. Accessed 29 May 2018.

15. Santos GM, Makofane K, Arreola S, Do T, Ayala G. Reductions in access to HIV prevention and care services associated with arrest and conviction in a global survey of men who have sex with men. Sex Transm Infect. 2017; 93(1):62-4. https://doi.org/10.1136/sextrans-2015-052386.

16. Ayala G, Santos GM. Will the global HIV response fail gay, bisexual men, and other men who have sex with men? J Int AIDS Soc. 2016;19:21098. https:// doi.org/10.7448/IAS.19.1.21098.

17. Ayala G, Makofane K, Do TD, Santos GM, Beck J, Scheim Al, Hebert P, Arreola S. Rights in Action: Access to HIV Services Among Men who have Sex with Men. Policy Brief published by LINKAGES at FHI360 and supported by USAID/PEPFAR. 2015. https://www.fhi360.org/sites/default/files/media/ documents/linkages-msm-rights-in-action.PDF. Accessed 11 Jan 2019 
18. World Health Organization. Values and Preferences of MSM: The Use of Antiretroviral Therapy as Prevention: World Health Organization; 2014. http://www.who.int/iris/handle/10665/128117. Accessed 11 Jan 2019

19. Baer J, Butler J, Ayala G, editors. Implementing Comprehensive HIV and STI Programmes with Men who have Sex with Men: Practical Guidance for Collaborative Interventions. New York: United Nations Population Fund; 2015.

20. Bellino MJ. The Risks We Are Willing to Take: Youth Civic Development in "Postwar" Guatemala. Voices in Education: The Blog of Harvard Education Publishing. 2015. http://hepg.org/blog/the-risks-we-are-willing-to-takeyouth-civic-devel. Accessed 29 May 2018.

21. DeJong J, Mahfoud Z, Khoury D, Barbir F, Afifi RA. Ethical considerations in HIV/AIDS biobehavioral surveys that use respondent-driven sampling: illustrations from Lebanon. Health Policy. Ethics. 2009;99:1562-6.

22. DiClemente RJ, McDermott Sales J, Borek N. Barriers to adolescents' participation in HIV biomedical prevention research. J Acquir Immune Defic Syndr. 2010;54(Suppl 1):S12-7. https://doi.org/10.1097/QAl.0b013e3181e1e2c0.

23. Paskett ED, Reeves KW, McLaughlin JM, Katz ML, Scheck McAlearney A, Ruffin MT, Hughes Halbert C, Merete C, Davis F, Gehlert S. Recruitment of minority and underserved populations in the United States: the Centers for Population Health \& Health Disparities experience. Contemp Clin Trials. 2008;29(6):847-61. https://doi.org/10.1016/j.cct.2008.07.006.

24. Spieldenner AR, Sprague L, Hampton A, Smith-Davis M, Peavy D, Bagchi A Cardell B, Johnson V, Brown G, Brewer R. From consumer to communitybased researcher: lessons from the PLHIV Stigma Index. In: Kellett P, editor. Narrating Patienthood: Engaging Diverse Voices on Deeper Cultural Health Narratives. Lexington Studies in Health Communication. New York: Rowman \& Littlefield; 2018.

25. McAdam D. The biographical consequences of activism. Am Sociol Rev. 1989;54(5):744-60

26. Rabkin JG, MCElhiney MC, Harrington M, Horn T. Trauma and growth: impact of AIDS activism. AIDS Res Treat. 2018;2018:9696725. https:/doi.org/10.1155/ 2018/9696725.

27. Gibbs A, Willan S, Jama-Shai N, Washington L, Jewkes R. Eh! I felt I was sabotaged!': facilitators' understandings of success in a participatory HIV and IPV prevention intervention in urban South Africa. Health Educ Res. 2015; 30(6):985-95.

28. Hebert-Beirne J, Felner JK, Kennelly J, Eldeirawi K, Mayer A, Alexander S, Castaneda YD, Castaneda D, Persky VD, Chavez N, Birman D. Partner development praxis: the use of transformative communication spaces in a community-academic participatory action research effort in a Mexican ethnic enclave in Chicago. Action Res. 2018;16(4):414-36. https://doi.org/10. $1177 / 1476750317695413$

29. Council on Education for Public Health. Accreditation Criteria. Schools of Public Health \& Public Health Programs. 2016. https://storage.googleapis. com/media.ceph.org/wp_assets/2016.Criteria.pdf. Accessed 17 Jan 2019

30. Cook T, Roche B. Editorial. Educ Action Res. 2017;25(4):467-72. https://doi. org/10.1080/09650792.2017.1358516.

Ready to submit your research? Choose BMC and benefit from:

- fast, convenient online submission

- thorough peer review by experienced researchers in your field

- rapid publication on acceptance

- support for research data, including large and complex data types

- gold Open Access which fosters wider collaboration and increased citations

- maximum visibility for your research: over $100 \mathrm{M}$ website views per year

At $\mathrm{BMC}$, research is always in progress.

Learn more biomedcentral.com/submissions 